\title{
Lesiones por mordedura de perro. Absolución de la falta contra los intereses generales del artículo 631.1 del Código Penal. Sentencia AP Toledo 5/2014, de fecha 8 de enero de $2014^{1}$
}

Cristina Bécares Mendiola ${ }^{2}$

RESUMEN:

El comentario hace referencia a la Sentencia dictada por la Audiencia Provincial de Toledo en fecha 8 de enero de 2014, mediante la cual se confirma la Sentencia recaída en el Juzgado de Instrucción núm. 1 de Orgaz en el juicio de faltas 256/2012.

El juez "a quo" absuelve a la denunciada de una falta contra los intereses generales prevista y penada en el artículo 631.1 del Código Penal, defendiendo que la misma había previsto mecanismos de cautela para que su perro no estuviera suelto.

\section{SUMARIO:}

1. Hechos

2. Ilícito penal

3. Argumentación de la Sentencia comentada

4. Conclusiones

\footnotetext{
${ }^{1}$ http://www.derechoanimal.info/bbdd/Documentos/1346.pdf

${ }^{2}$ Abogada en ejercicio. Profesora asociada a la UAB. Licenciada en Derecho y Criminología. Máster en Derecho Animal y Sociedad ( $1^{\text {a }}$ edición). Miembro del grupo de investigación Animales, Derecho y Sociedad de la UAB. http://www.derechoanimal.info/images/pdf/CV-Alumni-Cristina-Becares.pdf
} 


\section{Hechos:}

Los hechos enjuiciados son los siguientes:

Sobre las 09.30 horas del día 30 de julio de 2012, Alonso paseaba con su bicicleta por Villafranca de los Caballeros (provincia de Toledo), al llegar a la altura de la calle Madridejos fue mordido en la pierna izquierda por un perro propiedad de Paloma que en ese momento se encontraba suelto y sin correa.

A causa de estos hechos, Alonso sufrió lesiones consistentes en mordedura en región "supramaleolar externa izquierda, que precisaron para su sanidad 82 días de curación, siendo 30 de ellos impeditivos para su actividad habitual, así como secuelas no estéticas consistentes en dolor y parestesias en región supramaleolar externa izquierda valoradas en 1 punto, y secuelas estéticas, consistentes en cicatriz postraumática eritematosa de $4 \times 1 \mathrm{~cm}$ en región supramaleolar externa izquierda, valoradas como perjuicio estético ligero en 2 puntos".

Por este motivo, Alonso interpuso denuncia contra Paloma, incoándose el Juicio de Faltas 256/2012 en el Juzgado de Instrucción número 1 de Orgaz por una falta contra los intereses generales, prevista y penada en el artículo 631.1 del Código Penal ${ }^{3}$. Consta como hecho probado en la Sentencia que antes del incidente el perro estaba atado con cadena dentro de la finca propiedad de Paloma, escapándose de la misma por estar la correa un poco holgada.

El día 2 de noviembre de 2012 recayó la Sentencia por la cual el Juez absolvió a Paloma de la falta contra los intereses generales del artículo 631.1 del Código Penal.

\footnotetext{
${ }^{3}$ Código Penal: http://www.derechoanimal.info/bbdd/Documentos/839.doc
} 
Ante esta Sentencia, dentro del plazo previsto, el denunciante formuló recurso de apelación, interesando que toda vez se le absuelve de la falta del 631.1 sea condenada por una falta de lesiones por imprudencia del artículo 621.3 del Código Penal. La Sentencia de la Audiencia Provincial confirmó y ratificó íntegramente la Sentencia recaída en primera instancia por entender que eran ajustados a derecho.

\section{Ilícito penal:}

Establece el artículo 631.1 del Código Penal que:

"Los dueños o encargados de la custodia de animales feroces o dañinos que los dejaren sueltos o en condiciones de causar mal serán castigados con la pena de multa de uno a dos meses."

Estamos ante una falta de peligro abstracto, es decir que no requiere un resultado lesivo o dañoso. Su castigo viene fundamentado por la "amenaza" que supone la acción tipificada. Por lo tanto, el tipo delictivo se consuma cuando el propietario o el poseedor del animal, como sujetos activos del tipo, no lo tienen bajo control.

La problemática existe en el momento de determinar qué animal es feroz 0 dañino. Según la Sentencia 6/2014 de la AP de Toledo, de fecha 13 de enero de $2014^{4}$, es requisito indispensable para la existencia de infracción que el animal en cuestión sea feroz o dañino, dejando fuera de la esfera del artículo 631.1 los animales que no sean considerados como tales.

\footnotetext{
${ }^{4}$ http://www.derechoanimal.info/bbdd/Documentos/1348.pdf
} 
Dicha Sentencia hace referencia a la definición que ofrece la Ley 50/1999, de 23 de diciembre, sobre Régimen Jurídico de la Tenencia de Animales Potencialmente Peligrosos ${ }^{5}$, que en su artículo 2 define:

"1. Con carácter genérico, se consideran animales potencialmente peligrosos todos los que, perteneciendo a la fauna salvaje, siendo utilizados como animales domésticos, o de compañía, con independencia de su agresividad, pertenecen a especies o razas que tengan capacidad de causar la muerte o lesiones a las personas o a otros animales y daños a las cosas.

2. También tendrán la calificación de potencialmente peligrosos, los animales domésticos o de compañía que reglamentariamente se determinen, en particular, los pertenecientes a la especie canina, incluidos dentro de una tipología racial, que por su carácter agresivo, tamaño o potencia de mandíbula tengan capacidad de causar la muerte o lesiones a las personas o a otros animales y daños a las cosas."

Por lo tanto, toda acción consistente en dejar suelto a un animal incluido en dicha definición, según la Sentencia referenciada, sería constitutiva de la falta prevista en el artículo 631.1.

En cuanto al resto de animales no incluidos dentro de la definición, deberán ser objeto de interpretación individual, a fin de verificar si dicho animal puede causar daños; muestra de ello es el argumento de la Sentencia de la Audiencia Provincial de Málaga 2/2008 de 2 de enero de $2008^{6}$ que en sus fundamentos de derecho afirma que:

\footnotetext{
${ }^{5}$ http://www.derechoanimal.info/bbdd/Documentos/205.pdf

${ }^{6}$ http://www.derechoanimal.info/bbdd/Documentos/1351.pdf
} 
"[...] la tipificación posible de los hechos enjuiciados únicamente resultaría procedente, siquiera por dolo eventual, al amparo del artículo 631-1 del Código Penal, pues es lo cierto que todos los animales, incluidos los domésticos, en ocasiones presentan reacciones no previsibles, pudiendo resultar dañinos y causar un mal."

Por lo tanto, el lícito penal vendrá integrado por el elemento objetivo, consistente tal como hemos detallado en la concurrencia de la acción típica, esto es dejar suelto a un animal feroz o dañino, o en condiciones de causar mal a personas o bienes ajenos; $y$, por otra parte por el elemento subjetivo.

Dicho elemento subjetivo viene integrado por el dolo, ya que la falta del artículo 631.1 requiere del conocimiento del sujeto activo de dejar al animal, que tiene en propiedad o posesión, suelto o en condiciones de causar un mal. La comisión del tipo por imprudencia no está prevista, por lo que en virtud del artículo 12 del Código Penal ${ }^{7}$ no podrán castigarse las conductas imprudentes.

En cuanto al desarrollo legislativo del tipo, se introdujo el artículo 631.1 del Código Penal mediante la Ley Orgánica 10/1995, de 23 de Noviembre, previendo pena de multa de 15 a 30 días. Posteriormente, mediante la Ley Orgánica 15/2003 se agravó la pena a la de multa de 20 a 30 días, y nuevamente mediante la Ley Orgánica 5/2010 se agravó a multa de uno a dos meses (redacción actual).

\section{Argumentación de la Sentencia comentada:}

En el caso de la Sentencia de la Audiencia Provincial de Toledo 5/2014 objeto de este comentario, la Magistrada, coincidiendo con la Sentencia recurrida,

\footnotetext{
${ }^{7}$ Art. 12 CP: "Las acciones u omisiones imprudentes sólo se castigarán cuando expresamente lo disponga la Ley."
} 
entiende que no concurren los requisitos para que el hecho sea castigado como falta de lesiones por imprudencia, toda vez que las lesiones sufridas por Alonso no fueron causadas por la denunciada, Paloma, sino por un perro de su propiedad.

Por otra parte, en aplicación de lo previsto en el artículo 8 del Código Penal prevalece en este caso la aplicación del artículo 631.1 sobre la del 621.3 del Código Penal, y ello por ser el tipo específico, prevaleciendo sobre el general.

En este caso el perro estaba suelto en una vía pública, considerando la Sala que causaba un peligro, pero no por ello debe condenarse automática. Atendiendo al tipo subjetivo, la denunciada no era consciente de la situación del perro, no tenía voluntad de que se diera la acción típica; Paula había dispuesto una medida de cautela de eficacia, recordemos que el perro estaba atado dentro de la finca mediante una correa, y dada la holgura de la misma, el perro se las ingenió para deshacerse de la atadura accediendo a la vía pública.

Por ello, no se dan todos los elementos del tipo, y consecuentemente no puede condenarse a la denunciada como autora de la falta prevista y penada en el artículo 631.1 del Código Penal.

La línea argumental de la Sentencia aquí comentada coincide con la de otras Audiencias Provinciales, tales como la recogida en la SAP de Burgos 417/2013 de fecha 3 de octubre de $2013^{8}$ :

"La acción ha de ser dolosa, bien de manera directa, bien eventual. Dicho dolo puede ser directo o eventual, sin necesidad de que sea específico o con la finalidad de causar mal a alguna persona, bastando la conciencia de que lo pueda causar en las circunstancias

\footnotetext{
${ }^{8}$ http://www.derechoanimal.info/bbdd/Documentos/1269.pdf
} 
en que deje al animal. Ahora bien, las acciones imprudentes (SAP Tarragona de 18 de diciembre de 2003, Sección 2a , recurso 1257/03. SAP de Murcia Sección $1^{a} 2$ de mayo de 2000 rec. 251/2002 etc.) nunca tendrán cabida en este artículo (ejemplos tener a un animal suelto en la casa y abrir alguien la puerta, escaparse, romper el animal la correa) sino en su caso en el artículo 621 del Código Penal, y en la mayoría de los casos, en el artículo 1905 del Código Civil $[\ldots] "$

La no concurrencia del ilícito penal no conlleva que no exista ilícito civil. De este modo, el aquí denunciante puede acudir a la jurisdicción civil, ya que tal y como prevé el artículo 1905 del Código Civil":

"El poseedor de un animal, o el que se sirve de él, es responsable de los perjuicios que causare, aunque se le escape o extravíe. Sólo cesará esta responsabilidad en el caso de que el daño proviniera de fuerza mayor o de culpa del que lo hubiese sufrido."

\section{Conclusiones:}

Si comparamos los hechos con otros juzgados recientemente, observaremos que el hecho determinante, para llegar a la conclusión a la que llegan tanto el Juzgado de Instrucción número 1 de Orgaz como posteriormente la SAP Toledo 5/2014, es que el perro inicialmente se encontraba en una propiedad privada y provisto de correa, por lo que nada podía hacer prever a la propietaria de la situación que aconteció.

\footnotetext{
${ }^{9}$ http://www.derechoanimal.info/bbdd/Documentos/605.doc
} 


\section{dA derecho ANIMAL la web center de los animales con derecho}

Diferente es el caso por ejemplo de la SAP Toledo $4 / 2014^{10}$, donde el propietario del animal, si bien lo tenía atado, lo dejaba en disposición de causar daños, toda vez que el animal se encontraba en un patio por donde transitaban personas ajenas al núcleo familiar y personal del propietario del animal "en funciones de vigilancia".

O casos como el de la SAP de Pontevedra 101/2013 de fecha 1 de octubre de $2013^{11}$, donde se castiga al propietario del animal por carecer de medios de sujeción "que permitiesen ejercer un control o custodia debida del mismo."; o la SAP de Albacete 252/2013 de fecha 2 de septiembre de $2013^{12}$, donde el vallado era discontinuo; o la SAP de Albacete 250/2013 de fecha 2 de septiembre de $2013^{13}$, donde el propietario del animal estaba suelto.

En mi opinión, considero más que acertada la postura adoptada tanto por el Juzgado de Instrucción como por la Audiencia Provincial de Toledo, ya que no existe dolo de la propietaria por cuanto llevó a cabo las medidas oportunas para que no se generase un peligro. Los hechos aquí enjuiciados respondían a un hecho imprevisible y no controlable por la propietaria, motivo por el cual no procede una condena en vía penal.

Terrassa, a 4 de marzo de 2014

\footnotetext{
${ }^{10}$ http://www.derechoanimal.info/bbdd/Documentos/1347.pdf

${ }^{11}$ http://www.derechoanimal.info/bbdd/Documentos/1266.pdf

${ }^{12}$ http://www.derechoanimal.info/bbdd/Documentos/1224.pdf

${ }^{13}$ http://www.derechoanimal.info/bbdd/Documentos/1224.pdf
} 